\title{
VERSÃO E ADAPTAÇÃO PARA O PORTUGUÊS BRASILEIRO DO QUESTIONÁRIO: CRENÇAS E ATITUDES SOBRE PREVENÇÃO DE PERDA AUDITIVA
}

\section{Translation and adaptation of the questionnaire "beliefs and attitudes on hearing loss prevention" into Brazilian Portuguese}

\author{
Luciana Bramatti ${ }^{(1)}$, Thais Catalani Morata ${ }^{(2)}$, Jair Mendes Marques ${ }^{(3)}$, Ulisses Gabriel Martini ${ }^{(4)}$
}

\begin{abstract}
RESUMO
Objetivo: validar a versão para língua portuguesa do questionário "Crenças e Atitudes sobre a Prevenção de Perdas Auditivas", desenvolvido pelo National Institute for Occupational Safety and Health in 1996. Método: a validação do questionário seguiu as seguintes etapas: tradução do idioma inglês para o português, pré-teste com um subgrupo de 10 trabalhadores, adaptação lingüística, revisão da equivalência gramatical e idiomática e processo inverso de tradução do português para o inglês, para verificar se houve descaracterização do questionário. Participaram do estudo 31 trabaIhadores de uma indústria frigorífica, 17 do sexo masculino e 14 do sexo feminino, com idade média de 29 anos e 7 meses. As questões utilizadas foram medidas seguindo a escala de Likert com cinco graus, onde 1 - corresponde a "concordo totalmente" e 5 - "discordo totalmente". A análise fatorial objetivou explicar a ligação entre um conjunto de variáveis correlacionadas. Os trabalhadores responderam ao primeiro questionário (Versão $A$ ) e num prazo de 15 dias responderam ao segundo questionário (Versão B). Resultados: a reprodutibilidade do instrumento foi demonstrada pelo índice geral de Alfa de Cronbach de 0, 8146 para o formulário A e 0, 8569 para o formulário B. As correlações foram significantes indicando a validade de construto e conteúdo da versão em Português Brasileiro para o seu uso com uma população trabalhadora. Conclusões: o questionário foi traduzido e adaptado para ser aplicado na população brasileira, denominado Crenças e Atitudes sobre a Prevenção de Perdas Auditivas, e servirá como instrumento na avaliação das atitudes e comportamento dos trabalhadores frente ao ruído e prevenção de perdas auditivas.
\end{abstract}

DESCRITORES: Audição; Perda Auditiva Provocada pelo Ruído; Dispositivos de Proteção das Orelhas

(1) Fonoaudióloga; Diretora da Clinica Comunicação; Mestre em Distúrbios da Comunicação pela Universidade Tuiuti do Paraná

(2) Fonoaudióloga; Professora do Programa de Pós-Graduação em Distúrbios da Comunicação da Universidade Tuiuti do Paraná; pesquisadora do National Institute for Occupational Safety and Health; Doutora em Distúrbios da Comunicação pela Universidade de Cincinatti.

(3) Engenheiro Químico, Doutor em Ciências Geodésicas pela Universidade Federal do Paraná e Professor do Programa de Pós-Graduação em Distúrbios da Comunicação da Universidade Tuiuti do Paraná;

(4) Administrador; Professor de Metodologia Científica e Metodologia da Pesquisa na Universidade do Oeste de Santa Catarina; Especialista em Educação e Docência no Ensino Superior pela Faculdade Exponencial-FIE, Especialista em Marketing pela Universidade do Oeste de Santa Catarina - UNOESC.

\section{INTRODUÇÃO}

Os trabalhadores acometidos com perda auditiva profissional podem estar sujeitos ao isolamento social, que é o resultado de comunicação prejudicada com a família e amigos; à diminuição na habilidade para monitorar o ambiente de trabalho (sinais

Dissertação de mestrado: Efetividade de treinamento com enfoque positivo em programa de conservação auditiva. Instituição: Universidade Tuiuti do Paraná. Ano de 2007.

Disclaimer: Os achados e conclusões deste artigo são dos autores e não representam necessariamente a visão do National Institute for Occupational Safety and Health.

Conflito de interesses: inexistente 
de advertência); ao risco mais alto de acidentes no local de trabalho e à qualidade reduzida de vida em função do zumbido inflexível ${ }^{1}$.

Segundo a Sociedade Brasileira de Otologia, a desinformação é um dos fatores que contribuem para o aumento dos problemas auditivos. A população brasileira ainda não tem uma cultura de prevenção, e, muitas vezes, expõe a audição a riscos desnecessários.

Este cenário sugere a necessidade de identificar o nível de informação dos trabalhadores a respeito dos prejuízos da exposição ao ruído no ambiente de trabalho e as atitudes dos mesmos, diante desta situação. Para tanto é necessário a utilização de um instrumento específico que realizasse esta função. No presente estudo foi realizada uma busca e seleção de um questionário que avaliasse tanto a crença de trabalhadores como suas atitudes frente ao ruído ocupacional e práticas para prevenção de perdas auditivas. Por não haver até o momento uma versão adaptada para o português brasileiro, optou-se então por realizar a validação do instrumento: "Beliefs and Attitudes on Hearing Loss Prevention" desenvolvido pelo National Institute for Occupational Safety and Health (NIOSH) em 1996.

A participação do pesquisador na adaptação de um instrumento é desejável, uma vez que permite citar os conceitos explorados, reformular as questões e evitar as locuções e expressões idiomáticas².

Para a validação de um instrumento de avaliação ${ }^{3}$, acreditam que somente uma tradução cuidadosa não é suficiente, pois os termos lingüísticos devem ser adequados às condições sociais e culturais da população a ser estudada, existe a necessidade de medidas psicométricas dentro de um contexto específico, levando-se em conta o fato que cada sociedade possui suas próprias crenças, hábitos e atitudes e seu comportamento reflete na cultura de um país. Sempre que se trata de um questionário, a linguagem deve ser clara e simples, porém não pode perder sua equivalência original e sua coerência.

Ao selecionar o questionário a ser utilizado, o pesquisador deve ter em mente os aspectos a serem abordados ${ }^{4}$. Eles consideram que um instrumento deve ser útil não somente para identificar a atitude de um indivíduo em um determinado momento de sua vida, mas também para determinar mudanças após uma intervenção terapêutica educativa. Destacam como um dos aspectos fundamentais na construção do instrumento o número de questões e o tempo necessário para o preenchimento, pois instrumentos muito longos dificultam sua utilização. Uma boa intervenção junto aos trabalhadores deve ser elaborada com instrumentos que contenham uma ideia central a ser veiculada. A partir daí todos os recursos didáticos de apoio devem ser utilizados como: faixas, cartazes, cartilhas, palestras, aplicação de questionários, etc. Todos, veiculados em linguagem adequada e interessante para o trabaIhador buscando repassar informações a respeito de prevenção auditiva e principalmente, estimulando a conscientização sobre os riscos ao que o mesmo está exposto.

O uso de um instrumento para avaliar as atitudes dos trabalhadores frente ao ruído é um importante recurso a ser utilizado pelos fonoaudiólogos no processo de investigação da exposição a níveis sonoros elevados devido a potencial necessidade de influenciar essas atitudes. Só conhecendo as dificuldades dos indivíduos diante do ruído poderemos ter condições de implementar um processo educativo dentro de um Programa para Prevenção de Perdas Auditivas. Para que tanto, é necessária uma versão traduzida e adaptada para o português brasileiro.

Sendo assim, o objetivo da presente pesquisa foi adaptar e validar para a língua portuguesa, o questionário "Beliefs And Attitudes On Hearing Loss Prevention".

\section{MÉTODO}

Participaram desta pesquisa 31 trabalhadores, aproximadamente $30 \%$ da população, constituindo amostra aleatória obtida de uma população de 110 trabalhadores, de ambos os sexos (17 do sexo masculino e 14 do sexo feminino); com idade entre 18 e 48 anos (média de 29 anos e 7 meses); trabaIhadores do setor de Presuntaria de uma indústria frigorífica do município de Chapecó, estado de Santa Catarina. O critério de inclusão foi a escolha do setor com maior número de casos de perda auditiva (32\%) com características de exposição ao ruído e com o maior nível de pressão sonora (96 $\mathrm{dBA}$ ), dentre todos os setores do frigorífico. Inicialmente a pesquisadora realizou uma reunião com a gerência da empresa e setor de Medicina e Segurança do Trabalho para esclarecer sobre os objetivos da pesquisa. Na mesma ocasião, entregou ofício pedindo autorização para a realização da pesquisa, além de anexar uma cópia do questionário a ser aplicado. Após aprovação do estudo, nas datas e horários pré-estabelecidos, a pesquisadora compareceu à empresa para aplicação dos questionários. Sempre acompanhada de um profissional da Segurança do Trabalho onde foram esclarecidos os objetivos da pesquisa e como deveria ser o preenchimento do questionário.

Duas versões do questionário "Crenças e Atitudes sobre Prevenção de Perdas Auditivas (em inglês Beliefs and Attitudes on Hearing Loss 
Prevention) foram desenvolvidas por contrato para o National Institute for Occupational Safety and Health ${ }^{1}$, dos Estados Unidos ${ }^{1,5}$. Cada versão do questionário ( $\mathrm{A}$ e $\mathrm{B}$ ) consiste de vinte e oito questões, as quais são subdivididas em dez áreas temáticas, apresentadas nas Figuras 1 e 2.
As respostas são reações a afirmações, emitidas por meio da escala de Likert com cinco graus, onde 1 - está "concordo plenamente", 2 - "concordo", 3 - "não concordo nem discordo", 4 - "discordo" e 5 - "discordo totalmente".

\section{QUESTIONÁRIO A}

\section{Válido até: 13/06/2004}

A carga (média de tempo) desta coleta de informações é 12 minutos por resposta, incluindo o tempo para instruções de revisão, pesquisando fontes de dados existentes, reunindo e mantendo os dados necessários, e completando e revisando a coleta de informações. Um órgão não pode conduzir ou ser responsável, e não é exigido que uma pessoa responda a uma coleta de informações, a menos que apresente um número válido de OMB. Envie comentários a respeito desta avaliação de carga ou qualquer outro aspecto desta coleta de informações, incluindo sugestões para reduzir esta carga para CDC, Project Clearance Officer, 1600 Clifton Rd., M/S D24, Atlanta, GA 30333, ATTN: PRA(0920). Não envie o formulário completo para este endereço.

Nome: Data: Data de nascimento:

Ocupação:

Por favor, leia cada item e circule o número que melhor descreve sua opinião sobre a afirmação. Lembre-se: não há resposta certa ou errada! Estamos interessados em suas opiniões.

\begin{tabular}{|c|c|c|c|c|c|}
\hline & 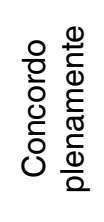 & 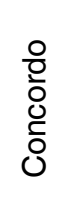 & 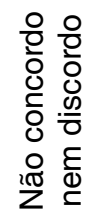 & 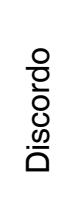 & 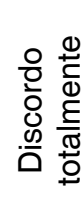 \\
\hline $\begin{array}{l}\text { 1. Penso que posso trabalhar perto de barulho alto sem que } \\
\text { isso cause danos a minha audição. }\end{array}$ & 5 & 4 & 3 & 2 & 1 \\
\hline $\begin{array}{l}\text { 2. Seria mais difícil para as pessoas conversarem comigo se eu } \\
\text { perdesse parte da minha audição. }\end{array}$ & 1 & 2 & 3 & 4 & 5 \\
\hline $\begin{array}{l}\text { 3. Onde eu trabalho há protetores auditivos prontamente } \\
\text { disponíveis para eu usar. }\end{array}$ & 1 & 2 & 3 & 4 & 5 \\
\hline $\begin{array}{l}\text { 4. Nem sempre posso dizer quando preciso usar protetores } \\
\text { auditivos. }\end{array}$ & 5 & 4 & 3 & 2 & 1 \\
\hline $\begin{array}{l}\text { 5. Eu estou convencido de que posso evitar a perda de audição } \\
\text { usando protetores auditivos. }\end{array}$ & 1 & 2 & 3 & 4 & 5 \\
\hline $\begin{array}{l}\text { 6. Protetores externos são muito quentes e pesados para eu } \\
\text { usar no meu trabalho. }\end{array}$ & 1 & 2 & 3 & 4 & 5 \\
\hline $\begin{array}{l}\text { 7. É difícil para ouvir sinais de advertência como back-up beeps } \\
\text { se eu estiver usando protetores auditivos. }\end{array}$ & 5 & 4 & 3 & 2 & 1 \\
\hline $\begin{array}{l}\text { 8. Não posso usar protetores porque preciso ouvir as pessoas } \\
\text { falando comigo enquanto trabalho. }\end{array}$ & 5 & 4 & 3 & 2 & 1 \\
\hline $\begin{array}{l}\text { 9. Conseguir protetores auditivos para usar no trabalho não é } \\
\text { conveniente para mim. }\end{array}$ & 5 & 4 & 3 & 2 & 1 \\
\hline $\begin{array}{l}\text { 10. Não pretendo usar protetores quando eu estiver próximo a } \\
\text { ferramentas ou equipamentos que reproduzam altos ruídos. }\end{array}$ & 5 & 4 & 3 & 2 & 1 \\
\hline $\begin{array}{l}\text { 11. Meus colegas geralmente usam protetores auditivos quando } \\
\text { trabalham em ambiente com barulho arriscado. }\end{array}$ & 1 & 2 & 3 & 4 & 5 \\
\hline
\end{tabular}




\begin{tabular}{|c|c|c|c|c|c|}
\hline & 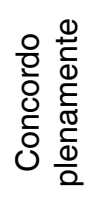 & $\begin{array}{l}\text { 음 } \\
\text { 은 } \\
\text { 잉 }\end{array}$ & 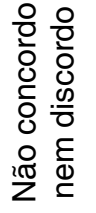 & $\begin{array}{l}\text { 음 } \\
\text { 음 } \\
\frac{-4}{0}\end{array}$ & 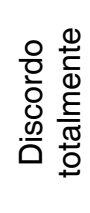 \\
\hline 12. Acredito que sei como ajustar e usar os protetores auditivos. & 1 & 2 & 3 & 4 & 5 \\
\hline $\begin{array}{l}\text { 13. Acredito que a exposição ao barulho alto pode prejudicar } \\
\text { minha audição. }\end{array}$ & 1 & 2 & 3 & 4 & 5 \\
\hline $\begin{array}{l}\text { 14. Não penso que seria uma grande desvantagem perder parte } \\
\text { da minha audição por ter trabalhado em ambiente muito } \\
\text { barulhento. }\end{array}$ & 5 & 4 & 3 & 2 & 1 \\
\hline $\begin{array}{l}\text { 15. Posso dizer quando um protetor interno precisa ser } \\
\text { substituído. }\end{array}$ & 1 & 2 & 3 & 4 & 5 \\
\hline $\begin{array}{l}\text { 16. Não posso proteger minha audição a menos que eu use } \\
\text { protetores auditivos em ambientes muito barulhentos. }\end{array}$ & 1 & 2 & 3 & 4 & 5 \\
\hline $\begin{array}{l}\text { 17. Protetores externos fazem muita pressão em minhas orelhas } \\
\text { para serem confortáveis. }\end{array}$ & 5 & 4 & 3 & 2 & 1 \\
\hline $\begin{array}{l}\text { 18. Usar protetores não me priva de ouvir sons importantes feitos } \\
\text { pelas ferramentas ou máquinas. }\end{array}$ & 1 & 2 & 3 & 4 & 5 \\
\hline $\begin{array}{l}\text { 19. Posso entender as falas suficientemente bem para fazer meu } \\
\text { trabalho enquanto estou usando protetores. }\end{array}$ & 1 & 2 & 3 & 4 & 5 \\
\hline $\begin{array}{l}\text { 20. No trabalho, posso escolher entre vários e diferentes } \\
\text { protetores para usar. }\end{array}$ & 5 & 4 & 3 & 2 & 1 \\
\hline $\begin{array}{l}\text { 21. Geralmente uso protetores sempre que estou trabalhando } \\
\text { perto de barulho alto ou equipamento barulhento. }\end{array}$ & 1 & 2 & 3 & 4 & 5 \\
\hline $\begin{array}{l}\text { 22. Meus colegas geralmente não usam protetores quando } \\
\text { precisam trabalhar em áreas barulhentas. }\end{array}$ & 5 & 4 & 3 & 2 & 1 \\
\hline $\begin{array}{l}\text { 23. Se meus colegas de trabalho perguntassem eu poderia } \\
\text { mostrar a eles a maneira correta de ajustar e usar protetores } \\
\text { auditivos. }\end{array}$ & 1 & 2 & 3 & 4 & 5 \\
\hline $\begin{array}{l}\text { 24. Se eu realmente quiser preservar minha audição, é } \\
\text { importante que eu use protetores auditivos todas as vezes } \\
\text { que eu estiver perto de barulho alto. }\end{array}$ & 1 & 2 & 3 & 4 & 5 \\
\hline $\begin{array}{lllll}\text { 25. } & \begin{array}{l}\text { Protetores podem ser confortáveis se ajustados } \\
\text { corretamente. }\end{array}\end{array}$ & 1 & 2 & 3 & 4 & 5 \\
\hline $\begin{array}{l}\text { 26. Mesmo quando o local não é barulhento algumas vezes é } \\
\text { difícil para mim ouvir quando as pessoas estão falando } \\
\text { comigo. }\end{array}$ & 5 & 4 & 3 & 2 & 1 \\
\hline 27. Protetores auditivos não são muito caros para eu comprar. & 1 & 2 & 3 & 4 & 5 \\
\hline $\begin{array}{l}\text { 28. Se eu tivesse um protetor auditivo comigo eu o usaria todas } \\
\text { as vezes que estivesse perto de qualquer barulho que fosse } \\
\text { alto o suficiente para prejudicar minha audição. }\end{array}$ & 1 & 2 & 3 & 4 & 5 \\
\hline
\end{tabular}

Figura 1 - Questionário versão A - original 


\section{QUESTIONÁRIO B}

\section{Formulário aprovado em 13/06/2002 OMB № 0920-0552}

\section{Válido até: 13/06/2004}

A carga (média de tempo) desta coleta de informações é 12 minutos por resposta, incluindo o tempo para instruções de revisão, pesquisando fontes de dados existentes, reunindo e mantendo os dados necessários, e completando e revisando a coleta de informações. Um órgão não pode conduzir ou ser responsável, e não é exigido que uma pessoa responda a uma coleta de informações, a menos que apresente um número válido de OMB. Envie comentários a respeito desta avaliação de carga ou qualquer outro aspecto desta coleta de informações, incluindo sugestões para reduzir esta carga para CDC, Project Clearance Officer, 1600 Clifton Rd., M/S D24, Atlanta, GA 30333, ATTN: PRA(0920). Não envie o formulário completo para este endereço.
Nome:
Data:
Data de nascimento:

Ocupação:

Por favor, leia cada item e circule o número que melhor descreve sua opinião sobre a afirmação. Lembre-se: não há resposta certa ou errada! Estamos interessados em suas opiniões.

\begin{tabular}{|c|c|c|c|c|c|}
\hline & 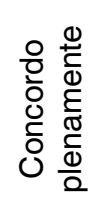 & $\begin{array}{l}\text { 임 } \\
0 \\
0 \\
0 \\
0\end{array}$ & 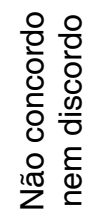 & 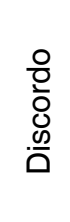 & 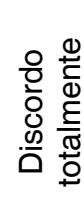 \\
\hline $\begin{array}{l}\text { 1. Não penso que tenho de usar protetores auditivos sempre } \\
\text { que estou trabalhando em ambientes com barulho alto. }\end{array}$ & 5 & 4 & 3 & 2 & 1 \\
\hline $\begin{array}{l}\text { 2. Não seria mais difícil para as pessoas conversarem comigo } \\
\text { se eu perdesse parte da minha audição. }\end{array}$ & 5 & 4 & 3 & 2 & 1 \\
\hline $\begin{array}{l}\text { 3. Protetores auditivos não estão prontamente disponíveis para } \\
\text { que eu possa usa-los onde trabalho. }\end{array}$ & 5 & 4 & 3 & 2 & 1 \\
\hline 4. Sei quando eu deveria usar protetores auditivos. & 1 & 2 & 3 & 4 & 5 \\
\hline $\begin{array}{l}\text { 5. Se eu usar protetores auditivos posso proteger minha } \\
\text { audição de barulho alto. }\end{array}$ & 1 & 2 & 3 & 4 & 5 \\
\hline $\begin{array}{l}\text { 6. Protetores internos são desconfortáveis para usar mesmo } \\
\text { quando bem ajustados. }\end{array}$ & 5 & 4 & 3 & 2 & 1 \\
\hline $\begin{array}{l}\text { 7. Mesmo quando estou usando protetores auditivos, ainda } \\
\text { posso ouvir os "back-up beeps" ou outros sinais de } \\
\text { advertência. }\end{array}$ & 1 & 2 & 3 & 4 & 5 \\
\hline $\begin{array}{l}\text { 8. Ainda posso ouvir as pessoas falando comigo enquanto faço } \\
\text { meu trabalho, mesmo quando estou usado meus protetores } \\
\text { auditivos. }\end{array}$ & 1 & 2 & 3 & 4 & 5 \\
\hline $\begin{array}{l}\text { 9. É conveniente eu conseguir protetores auditivos para usar no } \\
\text { trabalho. }\end{array}$ & 1 & 2 & 3 & 4 & 5 \\
\hline $\begin{array}{l}\text { 10. Pretendo usar protetores auditivos quando estou perto de } \\
\text { ferramentas ou equipamentos ruidosos. }\end{array}$ & 1 & 2 & 3 & 4 & 5 \\
\hline $\begin{array}{l}\text { 11. Meus colegas de trabalho geralmente não usam protetores } \\
\text { auditivos quando trabalham em ambiente com barulho } \\
\text { arriscado. }\end{array}$ & 5 & 4 & 3 & 2 & 1 \\
\hline $\begin{array}{l}\text { 12. Não tenho certeza que sei como ajustar e usar protetores } \\
\text { auditivos. }\end{array}$ & 5 & 4 & 3 & 2 & 1 \\
\hline $\begin{array}{l}\text { 13. Se eu não proteger meus ouvidos, o barulho alto pode } \\
\text { prejudicar minha audição. }\end{array}$ & 1 & 2 & 3 & 4 & 5 \\
\hline $\begin{array}{l}\text { 14. Não me aborreceria se eu perdesse parte da minha audição } \\
\text { por trabalhar em ambiente barulhento. }\end{array}$ & 5 & 4 & 3 & 2 & 1 \\
\hline
\end{tabular}




\begin{tabular}{|c|c|c|c|c|c|}
\hline & 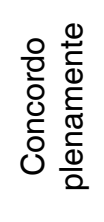 & $\begin{array}{l}\text { 음 } \\
\text { ㅁ } \\
\text { 당 }\end{array}$ & 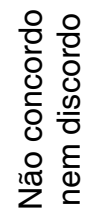 & $\begin{array}{l}\frac{0}{0} \\
\frac{0}{0} \\
0\end{array}$ & 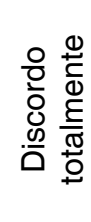 \\
\hline $\begin{array}{l}\text { 15. Não posso dizer quando um protetor interno ou externo } \\
\text { precisa ser substituído. }\end{array}$ & 5 & 4 & 3 & 2 & 1 \\
\hline $\begin{array}{l}\text { 16. Não perderei minha audição se eu usar protetores auditivos } \\
\text { em ambientes muito barulhentos. }\end{array}$ & 1 & 2 & 3 & 4 & 5 \\
\hline $\begin{array}{l}\text { 17. Posso encontrar um protetor externo que não seja muito } \\
\text { quente ou pesado para eu usar. }\end{array}$ & 1 & 2 & 3 & 4 & 5 \\
\hline $\begin{array}{l}\text { 18. Não posso ouvir barulhos que acusem problemas nas minhas } \\
\text { máquinas ou ferramentas se eu usar protetores auditivos. }\end{array}$ & 5 & 4 & 3 & 2 & 1 \\
\hline $\begin{array}{l}\text { 19. Não posso ouvir as falas suficientemente bem para fazer meu } \\
\text { trabalho se estou usando protetores auditivos. }\end{array}$ & 5 & 4 & 3 & 2 & 1 \\
\hline $\begin{array}{l}\text { 20. Não consigo encontrar um protetor auditivo que eu goste de } \\
\text { usar, porque não há uma variedade grande o suficiente para } \\
\text { eu escolher em meu local de trabalho. }\end{array}$ & 5 & 4 & 3 & 2 & 1 \\
\hline $\begin{array}{l}\text { 21. Geralmente não uso protetores auditivos quando trabalho em } \\
\text { ambiente barulhento. }\end{array}$ & 5 & 4 & 3 & 2 & 1 \\
\hline $\begin{array}{l}\text { 22. Meus colegas de trabalho geralmente não usam protetores } \\
\text { auditivos quando precisam trabalhar em áreas barulhentas. }\end{array}$ & 1 & 2 & 3 & 4 & 5 \\
\hline $\begin{array}{l}\text { 23. Não acho que eu poderia mostrar a um colega a maneira } \\
\text { correta de ajustar e usar protetores auditivos. }\end{array}$ & 5 & 4 & 3 & 2 & 1 \\
\hline $\begin{array}{l}\text { 24. Preciso usar protetores auditivos todas as vezes que estiver } \\
\text { em ambiente barulhento se eu realmente quiser mantes } \\
\text { minha audição. }\end{array}$ & 1 & 2 & 3 & 4 & 5 \\
\hline $\begin{array}{l}\text { 25. Se preciso usar um protetor externo posso conseguir um que } \\
\text { possa ser ajustado para que não haja muita pressão em } \\
\text { meus ouvidos. }\end{array}$ & 1 & 2 & 3 & 4 & 5 \\
\hline $\begin{array}{l}\text { 26. Mesmo em ambiente quieto, às vezes tenho dificuldades em } \\
\text { ouvir o que as pessoas estão dizendo. }\end{array}$ & 5 & 4 & 3 & 2 & 1 \\
\hline 27. Protetores auditivos são muito caros para eu comprar. & 5 & 4 & 3 & 2 & 1 \\
\hline $\begin{array}{l}\text { 28. Mesmo se eu tivesse um comigo, eu provavelmente não } \\
\text { usaria um protetor auditivo todas as vezes que eu estivesse } \\
\text { perto de qualquer barulho que fosse alto o suficiente para } \\
\text { prejudicar minha audição. }\end{array}$ & 5 & 4 & 3 & 2 & 1 \\
\hline
\end{tabular}

Figura 2 - Questionário versão B - original

O processo de validação é constituído de várias etapas, sendo que inicialmente foi solicitado a um professor bilíngüe para que o mesmo traduzisse o questionário do inglês para o português.

Depois de efetuadas as análises, foram selecionados 10 (dez) trabalhadores (aleatoriamente) de outra empresa para integrarem o pré-teste do questionário, em horário que não interferisse em suas atividades laborais.

Os questionários do pré-teste foram aplicados pela pesquisadora em horário pré-determinado e, após a leitura e explicação do aplicador (sobre os objetivos da pesquisa e como deveriam ser efetuadas as respostas) foi solicitado aos trabaIhadores que respondessem o questionário, registrassem as dificuldades de interpretação, opinassem sobre a linguagem utilizada (se estava adequada e/ ou havia palavra ou expressão desconhecida), bem como, indicassem as dificuldades encontradas em respondê-lo.

Os trabalhadores responderam o questionário em que se investigaram suas atitudes diante do ruído e o uso do protetor auditivo. Relataram ter encontrado dificuldades em compreender algumas questões e as palavras desconhecidas pela maioria foram "protetor externo", que foi substituída por 
"protetor tipo concha" (em inglês), "protetor interno", substituído por "protetor tipo plug" e "backup beeps" por "apitos". A maioria dos trabalhadores demonstrou interesse na pesquisa e ao final da aplicação do instrumento fizeram alguns questionamentos sobre os níveis confortáveis de ruído e tipos de protetores auditivos utilizados.

Também foi avaliada a equivalência semântica (gramática e vocabulário) e cultural de cada item (experiências vivenciadas dentro do contexto cultural da sociedade), além do cuidado específico com as instruções de preenchimento e a coerência da apresentação.

A etapa seguinte foi redigir a versão final (Figuras 3 e 4) com os ajustes realizados por um professor de português, e posteriormente, encaminhada para um segundo professor bilíngüe (sem qualquer contato ou informação sobre a versão original), para que este procedesse ao processo inverso de tradução do português para o inglês, sendo revisada e comparada com a versão original por três profissionais (bilíngües) para verificação se houve qualquer descaracterização do questionário.

O presente estudo foi aprovado pelo Comitê de Ética do Programa de Pós-Graduação em Distúrbios da Comunicação da Universidade Tuiuti do Paraná, processo 072/2006.

A dimensionalidade do instrumento foi analisada por meio de uma análise de fator explorativo. A finalidade da escala utilizada foi explorar atitudes dos trabalhadores para o ruído, e o uso dos protetores auditivos. Os valores atribuídos às escalas refletem avaliações positivas ou negativas diante do ruído. Foram utilizados no cálculo dos escores por área e total do questionário.

Para determinar a validade do instrumento, foi realizada análise estatística com uma técnica chamada Análise Fatorial (Rotação Varimax). Já para verificar a confiabilidade, foi utilizado o Alfa de Cronbach.

Para todos os testes estatísticos foi adotado o nível de significância de $5 \%(\alpha=0,05)$ e para as análises foi utilizado o software Excel e "Statistica 6.0".

\section{RESULTADOS}

A equipe de especialistas que analisou as traduções apontou que houve correspondência nos itens traduzidos, equivalência semântica entre as duas traduções e ausência de dificuldades de tradução. Foram realizados ajustes nas poucas diferenças de concordância verbal. A contra-tradução com a versão original, não revelou necessidade de alterações em estruturas gramaticais, quando a versão em português foi traduzida para o inglês.

A análise fatorial teve como objetivo principal explicar a correlação, entre um conjunto de variáveis correlacionadas, em termos de um número pequeno de variáveis não-observáveis ou variáveis latentes. Ou ainda, a redução da dimensionalidade dos dados para identificar um pequeno número de fatores que explique a maior parte das variações observadas em um número muito maior de variáveis. Os fatores foram extraídos na ordem de importância, ou seja, do mais explicativo para o menos explicativo. A análise fatorial possui um alto grau de flexibilidade, fornecendo diversos métodos para extração de fator, rotação e cálculo dos escores fatoriais. Os resultados da análise fatorial da presente pesquisa são apresentados na Tabela 1. Na determinação do número de fatores foi utilizado o critério da raiz latente, também conhecido como critério de Kaiser, ou seja, são retidos apenas os fatores com raízes latentes ou autovalores maiores que 1. Para os pesos fatoriais foi utilizado o corte de $\pm 0,45$.

Antes da aplicação da análise fatorial, verificouse que a matriz de correlação utilizada é adequada, pois o teste de esfericidade de Bartlett resultou significante $(p<0,05)$ e a Medida de Adequacidade da Amostra resultou em MSA =0,6014 (acima do mínimo recomendado que é 0,5 ).

$\mathrm{Na}$ Tabela 2, estão presentes os resultados que testam a confiabilidade do instrumento. Como o valor desejável para o coeficiente de Cronbach é de no mínimo 0,70 os resultados obtidos comprovam a confiabilidade da escala para ser utilizada em pesquisas com trabalhadores brasileiros.

$\mathrm{Na}$ Figura 5, apresentam-se as análises realizadas por área temática, a partir da análise fatorial.

Os fatores (que geram as áreas temáticas) resultaram em conjuntos de questões totalmente diferentes dos Formulários originais, ou seja, as áreas temáticas propostas pelos Formulários $\mathrm{A} e$ B originais não são confirmadas nessa pesquisa, sendo proposto desta forma, uma nova caracterização das áreas temáticas (Figura 6). 


\section{QUESTIONÁRIO A: VALIDADO}

Nome:

Data:

Data de nascimento:

Ocupação:

Por favor, leia cada item e marque a alternativa que melhor descreve sua opinião sobre a afirmação. Lembre-se: não há resposta certa ou errada! Estamos interessados em suas opiniões.

\begin{tabular}{|c|c|c|c|c|c|}
\hline & 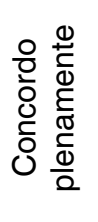 & $\begin{array}{l}\text { 윰 } \\
0 \\
0 \\
0 \\
0\end{array}$ & 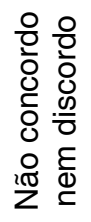 & $\begin{array}{l}\text { 음 } \\
\text { 음 } \\
. \frac{n}{0}\end{array}$ & 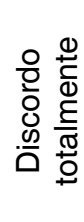 \\
\hline $\begin{array}{l}\text { 1. Eu penso que posso trabalhar perto de barulho alto sem que } \\
\text { isso cause danos à minha audição. }\end{array}$ & 5 & 4 & 3 & 2 & 1 \\
\hline $\begin{array}{l}\text { 2. Se eu perdesse parte da minha audição, seria mais difícil } \\
\text { para as pessoas conversarem comigo. }\end{array}$ & 1 & 2 & 3 & 4 & 5 \\
\hline $\begin{array}{l}\text { 3. Onde eu trabalho existem protetores auditivos facilmente } \\
\text { disponíveis para eu usar. }\end{array}$ & 1 & 2 & 3 & 4 & 5 \\
\hline $\begin{array}{l}\text { 4. Eu nem sempre sei dizer quando preciso usar protetores } \\
\text { auditivos. }\end{array}$ & 5 & 4 & 3 & 2 & 1 \\
\hline $\begin{array}{l}\text { 5. Eu estou convencido de que posso evitar a perda de audição } \\
\text { usando protetores auditivos. }\end{array}$ & 1 & 2 & 3 & 4 & 5 \\
\hline $\begin{array}{l}\text { 6. Protetores tipo concha são muito quentes e pesados para eu } \\
\text { usar no meu trabalho. }\end{array}$ & 1 & 2 & 3 & 4 & 5 \\
\hline $\begin{array}{l}\text { 7. É difícil ouvir sinais de alerta como apitos se eu estiver } \\
\text { usando protetores auditivos. }\end{array}$ & 5 & 4 & 3 & 2 & 1 \\
\hline $\begin{array}{l}\text { 8. Eu não posso usar protetores auditivos porque preciso ouvir } \\
\text { as pessoas falando comigo enquanto trabalho. }\end{array}$ & 5 & 4 & 3 & 2 & 1 \\
\hline $\begin{array}{l}\text { 9. Não é conveniente para mim conseguir protetores auditivos } \\
\text { para usar no trabalho. }\end{array}$ & 5 & 4 & 3 & 2 & 1 \\
\hline $\begin{array}{l}\text { 10. Eu não pretendo usar protetores quando eu estiver próximo a } \\
\text { ferramentas ou equipamentos barulhentos. }\end{array}$ & 5 & 4 & 3 & 2 & 1 \\
\hline $\begin{array}{l}\text { 11. Meus colegas geralmente usam protetores auditivos quando } \\
\text { trabalham no barulho alto. }\end{array}$ & 1 & 2 & 3 & 4 & 5 \\
\hline $\begin{array}{l}\text { 12. Eu acredito que sei como colocar e usar os protetores } \\
\text { auditivos. }\end{array}$ & 1 & 2 & 3 & 4 & 5 \\
\hline $\begin{array}{l}\text { 13. Eu acredito que a exposição ao barulho alto pode prejudicar } \\
\text { minha audição. }\end{array}$ & 1 & 2 & 3 & 4 & 5 \\
\hline $\begin{array}{l}\text { 14. Eu não acho que seria uma grande desvantagem perder } \\
\text { parte da minha audição por ter trabalhado no barulho alto. }\end{array}$ & 5 & 4 & 3 & 2 & 1 \\
\hline $\begin{array}{l}\text { 15. Eu sei dizer quando um protetor tipo plug (de inserção) } \\
\text { precisa ser trocado. }\end{array}$ & 1 & 2 & 3 & 4 & 5 \\
\hline $\begin{array}{l}\text { 16. Eu não posso proteger minha audição a não ser que eu use } \\
\text { protetores auditivos contra o barulho alto. }\end{array}$ & 1 & 2 & 3 & 4 & 5 \\
\hline $\begin{array}{l}\text { 17. Protetores tipo concha fazem muita pressão em minhas } \\
\text { orelhas para serem confortáveis. }\end{array}$ & 5 & 4 & 3 & 2 & 1 \\
\hline $\begin{array}{l}\text { 18. O uso de protetores auditivos não me impede de ouvir sons } \\
\text { importantes feitos pelas ferramentas ou máquinas. }\end{array}$ & 1 & 2 & 3 & 4 & 5 \\
\hline $\begin{array}{l}\text { 19. Eu posso entender alguém falando suficientemente bem para } \\
\text { fazer meu trabalho enquanto estou usando protetores. }\end{array}$ & 1 & 2 & 3 & 4 & 5 \\
\hline $\begin{array}{l}\text { 20. No trabalho, eu posso escolher entre vários tipos diferentes } \\
\text { de protetores para achar um que eu conseguia usar. }\end{array}$ & 5 & 4 & 3 & 2 & 1 \\
\hline $\begin{array}{l}\text { 21. Eu geralmente uso protetores quando estou trabalhando } \\
\text { perto de barulho alto ou equipamento barulhento. }\end{array}$ & 1 & 2 & 3 & 4 & 5 \\
\hline
\end{tabular}


22. Meus colegas geralmente não usam protetores quando precisam trabalhar em áreas barulhentas.

23. Se meus colegas de trabalho me pedissem, eu saberia mostrar a eles a maneira correta de colocar e usar protetores auditivos.

24. Se eu realmente quiser preservar minha audição, é importante que eu use protetores auditivos todas as vezes que eu estiver perto de barulho alto.

25. Protetores tipo plug (de inserção) podem ser confortáveis para o uso se ajustados corretamente.

26. Mesmo quando o local não é barulhento, algumas vezes é difícil para mim ouvir quando as pessoas estão falando comigo.

27. Protetores auditivos não são muito caros para eu comprar.

28. Se eu tivesse um protetor auditivo comigo, eu o usaria todas as vezes que estivesse perto de qualquer barulho que fosse alto o suficiente para prejudicar minha audição.

\begin{tabular}{|c|c|c|c|c|}
\hline 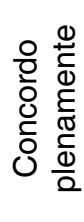 & $\begin{array}{l}\text { 음 } \\
\text { 엉 } \\
\text { 음 }\end{array}$ & 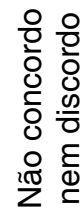 & 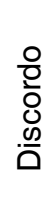 & 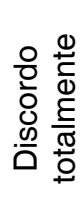 \\
\hline 5 & 4 & 3 & 2 & 1 \\
\hline 1 & 2 & 3 & 4 & 5 \\
\hline 1 & 2 & 3 & 4 & 5 \\
\hline 1 & 2 & 3 & 4 & 5 \\
\hline 5 & 4 & 3 & 2 & 1 \\
\hline 1 & 2 & 3 & 4 & 5 \\
\hline 1 & 2 & 3 & 4 & 5 \\
\hline
\end{tabular}

Figura 3 - Questionário versão A - validado 


\section{QUESTIONÁRIO B: VALIDADO}

Nome:

Data:

Data de nascimento:

Ocupação:

Por favor, leia cada item e marque a alternativa que melhor descreve sua opinião sobre a afirmação. Lembre-se: não há resposta certa ou errada! Estamos interessados em suas opiniões.

\begin{tabular}{|c|c|c|c|c|c|}
\hline & 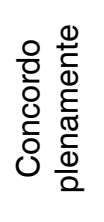 & 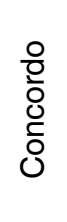 & 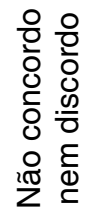 & $\begin{array}{l}\text { 음 } \\
\overline{0} \\
.0 \\
0\end{array}$ & 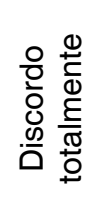 \\
\hline $\begin{array}{l}\text { Eu não acho que tenho de usar protetores auditivos sempre } \\
\text { que estou trabalhando no barulho alto. }\end{array}$ & 5 & 4 & 3 & 2 & 1 \\
\hline $\begin{array}{l}\text { 2. Não seria mais difícil para as pessoas conversarem comigo } \\
\text { se eu perdesse parte da minha audição. }\end{array}$ & 5 & 4 & 3 & 2 & 1 \\
\hline $\begin{array}{l}\text { 3. Protetores auditivos não estão facilmente disponíveis para } \\
\text { mim usá-los aonde trabalho. }\end{array}$ & 5 & 4 & 3 & 2 & 1 \\
\hline 4. Eu sei quando eu deveria usar protetores auditivos. & 1 & 2 & 3 & 4 & 5 \\
\hline $\begin{array}{l}\text { 5. Se eu usar protetores auditivos, eu posso proteger minha } \\
\text { audição contra barulhos altos. }\end{array}$ & 1 & 2 & 3 & 4 & 5 \\
\hline $\begin{array}{l}\text { 6. Protetores tipo plug (de inserção) são desconfortáveis para } \\
\text { usar, mesmo quando estão bem ajustados. }\end{array}$ & 5 & 4 & 3 & 2 & 1 \\
\hline $\begin{array}{l}\text { 7. Mesmo quando estou usando protetores auditivos, ainda } \\
\text { posso ouvir apitos ou outros sinais de alerta. }\end{array}$ & 1 & 2 & 3 & 4 & 5 \\
\hline $\begin{array}{l}\text { 8. Eu posso ouvir as pessoas falando comigo enquanto faço } \\
\text { meu trabalho mesmo quando estou usado meus protetores } \\
\text { auditivos. }\end{array}$ & 1 & 2 & 3 & 4 & 5 \\
\hline $\begin{array}{l}\text { 9. É conveniente para mim conseguir protetores auditivos para } \\
\text { usar no trabalho. }\end{array}$ & 1 & 2 & 3 & 4 & 5 \\
\hline $\begin{array}{l}\text { 10. Eu pretendo usar protetores auditivos quando estiver perto de } \\
\text { ferramentas ou equipamentos barulhentos. }\end{array}$ & 1 & 2 & 3 & 4 & 5 \\
\hline $\begin{array}{l}\text { 11. Meus colegas de trabalho geralmente não usam protetores } \\
\text { auditivos quando trabalham em ambiente com barulho muito } \\
\text { alto. }\end{array}$ & 5 & 4 & 3 & 2 & 1 \\
\hline $\begin{array}{l}\text { 12. Não tenho certeza de que eu sei como colocar e usar } \\
\text { protetores auditivos. }\end{array}$ & 5 & 4 & 3 & 2 & 1 \\
\hline $\begin{array}{l}\text { 13. Se eu não proteger meus ouvidos, o barulho alto pode } \\
\text { prejudicar minha audição. }\end{array}$ & 1 & 2 & 3 & 4 & 5 \\
\hline $\begin{array}{l}\text { 14. Eu não me aborreceria se eu perdesse parte da minha } \\
\text { audição por causa do barulho no meu trabalho. }\end{array}$ & 5 & 4 & 3 & 2 & 1 \\
\hline $\begin{array}{l}\text { 15. Eu não sei sempre que um protetor tipo plug ou tipo concha } \\
\text { precisa ser trocado. }\end{array}$ & 5 & 4 & 3 & 2 & 1 \\
\hline $\begin{array}{l}\text { 16. Eu não perderei minha audição se eu usar protetores } \\
\text { auditivos em ambientes barulhentos. }\end{array}$ & 1 & 2 & 3 & 4 & 5 \\
\hline $\begin{array}{l}\text { 17. Eu posso encontrar um protetor tipo concha que não seja } \\
\text { muito quente ou pesado para eu usar. }\end{array}$ & 1 & 2 & 3 & 4 & 5 \\
\hline $\begin{array}{l}\text { 18. Eu não consigo ouvir problemas nas minhas máquinas ou } \\
\text { ferramentas se eu uso protetores auditivos. }\end{array}$ & 5 & 4 & 3 & 2 & 1 \\
\hline $\begin{array}{l}\text { 19. Eu não posso ouvir conversas suficientemente bem para } \\
\text { fazer meu trabalho se eu uso protetores auditivos. }\end{array}$ & 5 & 4 & 3 & 2 & 1 \\
\hline $\begin{array}{l}\text { 20. Eu não consigo encontrar um protetor auditivo que eu goste } \\
\text { de usar, porque não há uma variedade grande para eu } \\
\text { escolher em meu local de trabalho. }\end{array}$ & 5 & 4 & 3 & 2 & 1 \\
\hline
\end{tabular}




\begin{tabular}{|c|c|c|c|c|c|}
\hline & 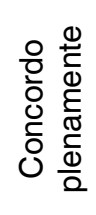 & $\begin{array}{l}\text { 음 } \\
\text { 은 } \\
\text { D }\end{array}$ & 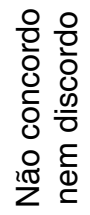 & $\begin{array}{l}\text { 음 } \\
\text { 음 } \\
\frac{\mathscr{D}}{0}\end{array}$ & 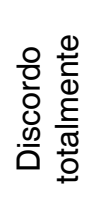 \\
\hline $\begin{array}{l}\text { 21. Eu geralmente não uso protetores auditivos quando trabalho } \\
\text { em perto de equipamento barulhento ou barulhos altos. }\end{array}$ & 5 & 4 & 3 & 2 & 1 \\
\hline $\begin{array}{l}\text { 22. Meus colegas de trabalho geralmente usam protetores } \\
\text { auditivos quando precisam trabalhar em áreas barulhentas. }\end{array}$ & 1 & 2 & 3 & 4 & 5 \\
\hline $\begin{array}{l}\text { 23. Eu não acho que saberia mostrar a um colega a maneira } \\
\text { correta de ajustar e usar protetores auditivos. }\end{array}$ & 5 & 4 & 3 & 2 & 1 \\
\hline $\begin{array}{l}\text { 24. Eu preciso usar protetores auditivos todas as vezes que } \\
\text { estiver perto de barulho alto se eu realmente quiser preservar } \\
\text { minha audição. }\end{array}$ & 1 & 2 & 3 & 4 & 5 \\
\hline $\begin{array}{l}\text { 25. Se eu precisar usar um protetor tipo concha eu posso } \\
\text { conseguir um que possa ser ajustado para não causar muita } \\
\text { pressão em meus ouvidos. }\end{array}$ & 1 & 2 & 3 & 4 & 5 \\
\hline $\begin{array}{l}\text { 26. Mesmo em ambientes quietos eu às vezes tenho dificuldades } \\
\text { em ouvir o que as pessoas estão me dizendo. }\end{array}$ & 5 & 4 & 3 & 2 & 1 \\
\hline 27. Protetores auditivos são muito caros para eu comprar. & 5 & 4 & 3 & 2 & 1 \\
\hline $\begin{array}{l}\text { 28. Mesmo se eu tivesse um protetor auditivo comigo, } \\
\text { provavelmente eu não o usaria todas as vezes que estivesse } \\
\text { perto de barulhos que fossem altos o suficiente para } \\
\text { prejudicar minha audição. }\end{array}$ & 5 & 4 & 3 & 2 & 1 \\
\hline
\end{tabular}

Figura 4 - Questionário versão B - validado 
Tabela 1 - Resultado da análise fatorial (Rotação Varimax): pesos fatoriais, autovalores e explicação de cada fator

\begin{tabular}{|c|c|c|c|c|c|c|c|c|c|c|}
\hline \multirow{2}{*}{ ITENS } & \multicolumn{10}{|c|}{ FATORES } \\
\hline & F1 & F2 & F3 & F4 & F5 & F6 & F7 & F8 & F9 & F10 \\
\hline 1 & 0,7187 & 0,1692 & 0,0311 & $-0,0313$ & $-0,0404$ & 0,0386 & 0,0393 & 0,1012 & 0,0252 & 0,0674 \\
\hline 2 & 0,2675 & 0,0541 & $-0,1288$ & $-0,1128$ & $-0,1171$ & $-0,0096$ & 0,8260 & 0,1391 & 0,0738 & $-0,1259$ \\
\hline 3 & 0,5915 & $-0,1754$ & 0,2090 & 0,3265 & 0,1936 & 0,0378 & 0,2075 & $-0,2274$ & 0,0500 & 0,0866 \\
\hline 4 & $-0,1682$ & 0,3550 & 0,2239 & 0,4652 & 0,4513 & $-0,3014$ & $-0,0053$ & $-0,0061$ & 0,0815 & 0,0779 \\
\hline 5 & 0,0130 & 0,5485 & $-0,1332$ & 0,5489 & 0,1387 & 0,0799 & 0,1030 & $-0,0111$ & $-0,1896$ & 0,1201 \\
\hline 6 & 0,3525 & 0,2043 & 0,2098 & 0,0422 & $-0,2307$ & $-0,1371$ & 0,6107 & $-0,4354$ & 0,0739 & 0,0852 \\
\hline 7 & $-0,0250$ & 0,6708 & 0,2960 & 0,0898 & $-0,0441$ & 0,3606 & 0,0926 & 0,0171 & 0,1085 & 0,1739 \\
\hline 8 & 0,2358 & 0,8017 & 0,1808 & $-0,0128$ & 0,0406 & 0,1285 & 0,0263 & 0,0149 & 0,0204 & 0,0195 \\
\hline 9 & $-0,0879$ & 0,7370 & 0,1812 & 0,0976 & 0,0604 & $-0,0232$ & 0,3003 & 0,1114 & 0,0129 & 0,0678 \\
\hline 10 & 0,0683 & 0,5963 & 0,1760 & $-0,0855$ & 0,1816 & $-0,1609$ & $-0,0069$ & 0,2434 & 0,5172 & 0,1850 \\
\hline 11 & 0,6892 & $-0,1285$ & $-0,0404$ & 0,3425 & 0,1484 & 0,0310 & 0,2300 & $-0,2415$ & $-0,0660$ & $-0,0689$ \\
\hline 12 & 0,8045 & 0,0633 & 0,1400 & 0,0498 & 0,0665 & 0,1799 & 0,2109 & 0,1605 & $-0,1255$ & 0,2437 \\
\hline 13 & 0,4973 & 0,3315 & $-0,0073$ & 0,3075 & 0,2746 & 0,0644 & $-0,1366$ & 0,0369 & $-0,0104$ & $-0,5187$ \\
\hline 14 & 0,4167 & 0,2223 & $-0,0193$ & 0,1166 & 0,1549 & 0,0869 & $-0,1868$ & 0,0197 & $-0,0857$ & 0,7314 \\
\hline 15 & $-0,0990$ & $-0,3241$ & 0,6444 & 0,0312 & $-0,0302$ & $-0,1291$ & 0,0408 & 0,3960 & $-0,1440$ & $-0,1430$ \\
\hline 16 & 0,1745 & 0,0358 & $-0,0362$ & 0,8061 & $-0,1639$ & $-0,0243$ & $-0,1459$ & $-0,0050$ & 0,2391 & $-0,0428$ \\
\hline 17 & 0,3112 & $-0,1371$ & 0,0667 & $-0,1403$ & 0,7451 & 0,1416 & $-0,0714$ & $-0,0902$ & $-0,1644$ & 0,2362 \\
\hline 18 & 0,1275 & 0,2384 & 0,8259 & $-0,0821$ & 0,2206 & 0,0452 & $-0,0135$ & $-0,1399$ & $-0,0718$ & 0,0579 \\
\hline 19 & 0,1699 & 0,2069 & 0,7585 & 0,0554 & 0,0035 & 0,2724 & 0,0073 & $-0,0257$ & 0,0860 & 0,0070 \\
\hline 20 & $-0,0611$ & 0,1538 & 0,0760 & $-0,0860$ & 0,0854 & 0,8364 & $-0,0472$ & $-0,0949$ & 0,0404 & 0,0308 \\
\hline 21 & 0,4900 & 0,3748 & 0,5918 & $-0,2216$ & 0,0178 & $-0,1346$ & $-0,1695$ & 0,0899 & $-0,0802$ & 0,0584 \\
\hline 22 & $-0,0311$ & 0,3330 & 0,0803 & 0,0250 & 0,7026 & 0,0319 & $-0,1721$ & 0,2418 & $-0,0732$ & $-0,1716$ \\
\hline 23 & 0,4911 & 0,2210 & 0,3713 & 0,3068 & $-0,1188$ & 0,2133 & 0,0332 & 0,2468 & $-0,3079$ & 0,0088 \\
\hline 24 & 0,2039 & 0,7850 & $-0,0713$ & 0,0798 & 0,0421 & 0,0766 & $-0,2397$ & 0,0256 & $-0,0918$ & $-0,2137$ \\
\hline 25 & 0,0362 & 0,1610 & 0,0196 & $-0,0178$ & 0,0644 & $-0,0934$ & 0,0421 & 0,8458 & 0,0061 & 0,0241 \\
\hline 26 & 0,3297 & 0,1954 & 0,4269 & 0,2972 & 0,0027 & 0,5276 & $-0,0344$ & $-0,0324$ & 0,1760 & $-0,0033$ \\
\hline 27 & 0,0052 & 0,0330 & 0,1020 & $-0,2037$ & 0,2077 & $-0,1538$ & $-0,1069$ & 0,0588 & $-0,7980$ & 0,0925 \\
\hline 28 & 0,7513 & 0,1140 & 0,1628 & $-0,1312$ & 0,0065 & $-0,2896$ & 0,0488 & $-0,1246$ & 0,1920 & $-0,0672$ \\
\hline Auto & 4,0867 & 3,9451 & 2,7822 & 1,8781 & 1,6912 & 1,6153 & 1,5250 & 1,4868 & 1,3029 & 1,1679 \\
\hline Expl. & 0,1460 & 0,1409 & 0,0994 & 0,0671 & 0,0604 & 0,0577 & 0,0545 & 0,0531 & 0,0465 & 0,0417 \\
\hline Prop.acum. & 0,1460 & 0,2869 & 0,3863 & 0,4534 & 0,5138 & 0,5715 & 0,6260 & 0,6791 & 0,7256 & 0,7673 \\
\hline
\end{tabular}

Tabela 2 - Resultado do alfa de cronbach para validação dos formulários A e B

\begin{tabular}{ccccc}
\hline FORMULÁRIO & $\mathbf{n}$ & MÉDIA & DESVIO PADRÃO & $\begin{array}{c}\text { ALFA DE } \\
\text { CRONBACH }\end{array}$ \\
\hline A & 31 & 58,48 & 12,01 & 0,8146 \\
B & 31 & 55,03 & 12,95 & 0,8569 \\
\hline
\end{tabular}

$\mathrm{n}=$ número de casos válidos 


\begin{tabular}{|c|c|}
\hline FATORES (ÁREAS TEMÁTICAS) & № DAS QUESTÕES (ITENS) \\
\hline F1 & $1,3,11,12,23,28$ \\
\hline F2 & $7,8,9,10,24$ \\
\hline F3 & $15,18,19,21$ \\
\hline F4 & $4,5,16$ \\
\hline F5 & 17,22 \\
\hline F6 & 20,26 \\
\hline F7 & 2,6 \\
\hline F8 & 25 \\
\hline F9 & 27 \\
\hline F10 & 13,14 \\
\hline
\end{tabular}

Figura 6 - Nova caracterização das áreas temáticas

\begin{tabular}{|l|c|}
\hline Área temática & $\begin{array}{c}\mathbf{n}^{\circ} \text { das questões } \\
\text { Versão A e B }\end{array}$ \\
\hline 1. Percepção sobre o risco e implicações de perda auditiva e uso do EPA & $1,3,11,12,23,28$ \\
\hline 2. Percepção sobre obstáculos, ação preventiva e auto-eficácia & $7,8,9,10,24$ \\
\hline 3. Percepção sobre interferência do uso do EPA no trabalho & $15,18,19,21$ \\
\hline 4. Percepção benefícios de uma ação preventiva & $4,5,16$ \\
\hline 5. Percepção a comodidade e normas sociais sobre uso do EPA & 17,22 \\
\hline 6. Percepção sobre conveniência e comunicação com o uso do EPA & 20,26 \\
\hline $\begin{array}{l}\text { 7. Percepção sobre obstáculos ação preventiva e conseqüências de uma } \\
\text { perda auditiva }\end{array}$ & 2,6 \\
\hline 8. Percepção sobre conforto com o uso do EPA & 25 \\
\hline 9. Percepção sobre disponibilidade do EPA & 27 \\
\hline 10. Percepção sobre suscetibilidade de adquirir perda auditiva e severidade & 13,14 \\
\hline
\end{tabular}

\section{Figura 5 - Dimensões (Áreas Temáticas) obtidas pela análise fatorial}

\section{DISCUSSÃO}

Não existia, até o momento, questionário específico, traduzido culturalmente adaptado para o Português Brasileiro e validado, capaz de avaliar as crenças e atitudes dos trabalhadores diante do ruído no ambiente de trabalho. A validação é um processo comumente longo que, no entanto, permite dispor de um instrumento equivalente ao original ${ }^{6}$. Utilizando tal metodologia é possível garantir a equivalência da fonte.

"Um questionário precisa ser confiável, válido e responsivo"7. A reprodutibilidade deste instrumento foi mostrada pelo índice geral de $a=0,75$. O entendimento das questões foi satisfatório, pois além dos trabalhadores não apresentarem dificuldades na hora do preenchimento do questionário, as correlações foram significantes indicando a validade de construção e conteúdo para o seu uso. As mudanças observadas nas áreas temáticas indicaram quais respostas estavam mais correlacionadas, ou seja, como uma resposta ajudava a predizer a outra, ocasionando desta forma, em conjuntos de questões diferentes do questionário original, porém correlacionados com o mesmo. A modificação das áreas temáticas não interferiu nos padrões de respostas quando comparados os dois questionários. Concordamos com os autores supracitados, quando enfatizam que um instrumento deve levar a um resultado igual ao avaliar o mesmo fato em diferentes circunstâncias, mensurar com fidelidade o que se propõe a avaliar e ser capaz de detectar mudanças no transcorrer do tempo ou relacionada a intervenções.

\section{CONCLUSÃO}

A análise da versão em português brasileiro do questionário "Crenças e Atitudes sobre Prevenção de Perdas Auditivas", elaborado por pesquisadores do NIOSH, revela que este é um instrumento válido e reprodutível para mensurar as atitudes dos trabaIhadores brasileiros diante da exposição ao ruído ocupacional. 


\section{ABSTRACT}

Purpose: to evaluate the Brazilian Portuguese version of the instrument "Beliefs and Attitudes on Hearing Loss Prevention", developed by the National Institute for Occupational Safety and Health in 1996. Method: the development of the Portuguese scale followed the following steps: translation from English into Brazilian Portuguese, pre-test with a group of 10 workers compared to the target population, linguistic adaptation, review of grammatical and idiomatic equivalence, and reverse translation into English in order to check that the instrument remained true to its original version. Following this elements, the Portuguese instrument was validated with the group of 31 workers. The participating workers came from a meat-packing company. Seventeen were males and 14 were females, and their mean age was 29 years and 7 months. The questions were constructed using a 5-point Likert scale where 1 meant "disagree completely" and 5 meant "agree completely." A factorial analysis was conducted in order to check construct validity of correlated questionnaire items. The participants responded to the first questionnaire (version A) and 15 days later responded to the second questionnaire (Version B). Results: the validity of the entire instrument was demonstrated by a Cronbach's Alpha of 0.8146 for the version A of the instrument and 0.8569 for the Version B. The significant correlations among related questionnaire items indicate the validity of its format and content for the intended usage with a Brazilian Portuguese version with a population of workers. Conclusions: the questionnaire was translated and adapted to Brazilian Portuguese and will facilitate the evaluation of attitudes and beliefs of Brazilian-Portuguese speaking workers towards noise and hearing loss prevention.

KEYWORDS: Hearing; Hearing Loss, Noise-induced; Ear Protective Devices

\section{REFERÊNCIAS}

1. NIOSH - National Institute for Occupational Safety And Health. Preventing occupational hearing loss - a practical guide. DHHS 1996; Publication No. $96-110$ p.1.

2. Bradley C. Translation of questionnaires for use in different languages and cultures. In: Bradley C. Handbook of psychology and diabetes. Churchill: Harwood, 1994:43-55.

3. Schmidt LP et al. Adaptação para a língua portuguesa do questionário Tinnitus Handicap Inventory: validade e reprodutibilidade. Revista Brasileira de Otorrinolaringologia. 2006; 72(6):808-10.

4. Melchiors AC et al. Medidas de avaliação da qualidade de vida em diabetes. Parte II: Instrumentos específicos. Seguim Farmacoter, Espanha. 2004; 2(2):59-72.

5. Stephenson R, Merry CJ et al. A comparison and contrast of workers' vs. health and safety professionals' attitudes and beliefs about preventing occupational hearing loss. NIOSH. [poster na internet]. National Hearing Conservation Association Annual Conference. Atlanta GA, Feb 25 - 27, 1999 [acesso em: 15 jan. 2007].Disponível em: <http:// www.cdc.gov/niosh/noise/nhca99f.ppt>.

6. Torres HC, Hortale VA, Schall VT. Validação dos questionários de conhecimento (DKN-A) e atitude (ATT-19) de Diabetes Mellitus. Revista de Saúde Pública, São Paulo. 2005 dec; 39:6.

7. Ferreira CAS'A, Cukier A. Avaliando a DPOC pela perspectiva do paciente. Jornal de Pneumologia, São Paulo. 2006; 32(2):7-8.

http://dx.doi.org/10.1590/S1516-18462011005000082

RECEBIDO EM: 07/10/2010

ACEITO EM: 31/03/2011

Endereço para correspondência:

Luciana Bramatti

Rua Lauro Muller, 281 D - Chapecó, SC

CEP: 89802-520

E-mail: luciana@clinicacomunicacao.com.br 